\title{
Epididymal Sperm Maturation in Bats with Prolonged Sperm Storage
}

\author{
Rodríguez-Tobón Ahiezer ${ }^{1}$, León-Galván Miguel A. ${ }^{2}$, Arenas-Ríos Edith ${ }^{3}$ \\ ${ }^{1}$ Postgraduate in Experimental Biology, Autonomous Metropolitan University-Iztapalapa, Iztapalapa, México \\ ${ }^{2}$ Department of Biology, Autonomous Metropolitan University-Iztapalapa, Iztapalapa, México \\ ${ }^{3}$ Department of Biology of Reproduction, Autonomous Metropolitan University-Iztapalapa, Iztapalapa, México
}

Email address:

ahiezerrod@yahoo.com.mx (Rodríguez-Tobón A.), león@xanum.uam.mx (León-Galván M. A.), editharenas2000@yahoo.com.mx (Arenas-Ríos E.)

\section{To cite this article:}

Rodríguez-Tobón Ahiezer, León-Galván Miguel A., Arenas-Ríos Edith. Epididymal Sperm Maturation in Bats with Prolonged Sperm Storage. Animal and Veterinary Sciences. Special Issue: Advances in Bat's Reproduction. Vol. 3, No. 1-2, 2015, pp. 1-7. doi: $10.11648 /$ j.avs.s.2015030101.11

\begin{abstract}
Epididymal sperm maturation is the process through which sperm acquire the potential to fertilize the egg. For most mammals, studies report that this process is completed before the sperm enter the cauda region of the epididymis; however, in some bat species, such as the Mexican big-eared bat (Corynorhinus mexicanus), this does not occur, as the process does not end until the sperm are inside the cauda of the epididymis, and thus is associated with a long storage period.
\end{abstract}

Keywords: Epididymis, Epididymal Sperm Maturation, Prolonged Sperm Storage, Bats

\section{Introduction}

The sperm are formed in the testes during spermatogenesis, but are not yet capable of fertilizing an oocyte as they continue to experience structural, physiological and biochemical changes or modifications after leaving the seminiferous tubules [1]. Later, in the epididymis, the sperm undergo a process called epididymal sperm maturation through which they acquire a marked increase in motility strength, lose the cytoplasmic droplet, increase their surface charge, show changes in lipid composition and, in some species, experience a massive remodeling of the acrosome form [2-10]. Together, all these changes prepare the sperm for capacitation and the acrosome reaction, which are necessary to obtain the ability to fertilize an oocyte $[1,6,10$ $13]$.

The epididymis is a simple, though somewhat convoluted, tubule that can measure from 3-to-80 $\mathrm{m}$ depending on the species [1, 14]. In most cases, it has three clearlydifferentiated anatomical regions: a) the initial segment, or caput, that receives the sperm and testicular fluid from the testicular efferent vessels; b) the corpus, which is narrower and connects to the final region; and, c) the cauda, which is of globular appearance and is responsible for storing the sperm until ejaculation $[1,6,10,13]$.
One of the most important functional characteristics of the epididymis involves secretion of specific proteins. This function is spatially-restricted to very specific segments of the organ, because each section of the epididymis is further divided into intra-regional segments bordered by connective tissue septa (CTS) [15]. Accordingly, in addition to providing support and stability to the organ itself, the CTS provide the microenvironment that the sperm require, given that gene expression and protein synthesis differ among the three regions $[1,15,16]$.

It has been reported that sperm maturation takes place between the caput and corpus of the epididymis, and that the mature sperm are then stored in the cauda until ejaculation $[10,17-21]$. This idea that the sperm of many mammalian species achieve maturity before reaching the caudal region emerged over 70 years ago (see Amman and Schanbacher [22]); however, recently-discovered morphophysiological evidence from the vespertilionid Mexican big-eared bat (Corynorhinus mexicanus) strongly suggests that the epididymal sperm maturation process requires an unusually long time compared to that reported for other mammals, and is not completed until the sperm are in the cauda. This process also appears to be associated with longer sperm 
storage time [23]. For these reasons, the objective of the present study was to identify the basic aspects of this process of epididymal sperm maturation in species of bats that have been described as having prolonged sperm storage in the epididymis.

\section{Biochemical Basis of Epididymal Sperm Maturation}

During maturation, the spermatozoa undergo intracellular changes in their calcium concentration, cyclic adenosine monophosphate content (cAMP), and tyrosine phosphorylation patterns, all of which are essential for the development of coordinated movement [20, 24-26]. The sperm's forward movement depends primarily on the mitochondrial function [20]; however, in order for the sperm to develop the ability to move progressively through the epididymis and later recognize the oocyte in the female genital tract, they must first go through a protein activation process, which is known as tyrosine phosphorylation [27-29].

\subsection{Tyrosine Phosphorylation}

Protein phosphorylation is a post-translational event that allows the cell to control several processes, including growth, the cell cycle, cytoskeleton assembly, and the modulation of ion transport, which function as adjustment mechanisms of biological activity [27-29]. In eukaryotic cells, most phosphorylations occur in serine (Ser) and threonine (Thr) protein residues and, though to a lesser degree, in those of tyrosine (Tyr). In mammalian sperm, it has been possible to determine that this occurs in a similar fashion, with a phosphorylation ratio of approximately 1000/100/1 for Ser, Thr and Tyr, respectively [27, 29]. The phosphorylation condition is controlled by the activity of protein kinases and phosphatases, where the former add a phosphate group and the latter remove it [27-29]. Studies have shown that phosphorylation of tyrosine residues is particularly important in sperm capacitation [27, 29], and is associated with the process of epididymal maturation, where certain phosphorylation/dephosphorylation events take place (which allow the spermatozoon to turn its function on, or off, like a "switch"), involving primarily the sperm flagellum proteins that participate in the acquisition of motility and the ability to fertilize the oocyte [29, 30].

However, studies of tyrosine phosphorylation have been conducted mainly in species in which the sperm maturation process is seen to end before the spermatozoa enter the epididymal cauda. In the case of $C$. mexicanus, it has been determined that tyrosine phosphorylation increases in sperm obtained from the cauda [31], clearly indicating that the sperm maturation process continues there. And this finding, in turn, may be related to the time that the sperm are stored in the cauda. However, the signaling pathways that allow tyrosine phosphorylation require the participation of certain molecules, such as cholesterol, calcium $\left(\mathrm{Ca}^{2+}\right)$, bicarbonate ions, progesterone, gamma-aminobutyric acid, and reactive oxygen species (ROS), among others [29, 32-34].

\subsection{Involvement of Reactive Oxygen Species (ROS) in Sperm Maturation}

Oxygen is essential for all aerobic organisms since it is the main source of energy acquired through oxidative metabolism. However, oxygen consumption generates various derivatives, including active forms of peroxidized oxygen metabolites and molecules, which together are known as reactive oxygen species (ROS) [34]. The ROS that result from the excitation of $\mathrm{O}_{2}$ form singlet oxygen or transfer 1,2 or 3 electrons to $\mathrm{O}_{2}$ to form the superoxide anion $\left(. \mathrm{O}_{2}-\right)$, hydrogen peroxide $\left(\mathrm{H}_{2} \mathrm{O}_{2}\right)$, and the hydroxyl radical (.OH-), respectively $[34,35]$. ROS are not necessarily toxic to the cell, for their toxicity depends on their concentration and the context in which they are produced [36]. Indeed, we now know that ROS are essential to the physiology of sperm in relation to such processes as maturation and capacitation [9, 12, 30, 34, 36-43].

Our working group has determined that ROS production in the epididymal sperm of $C$. mexicanus bats may well be involved in the sperm maturation process in the cephalic epididymis region. Moreover, ROS production persists in sperm obtained from the caudal region, suggesting and confirming the results reported by Cervantes et al. [23] In this mammal, unlike reports on other species, the sperm maturation process is completed in the caudal region [44]. In addition, ROS production does not depend on the activity of an NADPH oxidase which, apparently, is absent or inactive [44]. This finding suggests the involvement of cytochrome B5 reductase [33, 45]. Therefore, ROS production in the epididymal sperm of $C$. mexicanus could be of mitochondrial origin; alternatively, it would be necessary to confirm DUOX activity, as reported by Baker et al. [46].

Fortunately, the seminal plasma and sperm contain a whole battery of ROS scavengers, including such enzymes as superoxide dismutase (SOD), catalase (CAT), and glutathione peroxidase (GPX), as well as various substances whose activity is linked to CAT and SOD, such as $\alpha$-tocopherol, ascorbic acid, glutathione, pyruvate, taurine, hypotaurine, and albumin, which imbues them with the ability to regulate ROS growth [36, 47-53]).

There are studies of the participation of the antioxidant enzymes CAT, SOD and GPX in C. mexicanus that have measured the enzyme activity found in the epididymis, including the mechanism that modulates ROS during maturation and prolonged sperm storage, two patterns of enzymatic activity that appear according to the phase of the epididymal reproductive cycle. CAT activity in the epididymis is particularly high throughout the reproductive cycle, while SOD activity is present during sperm transit from the testes to the epididymis, and sperm maturation, but is almost completely absent from the cephalic and caudal epididymal regions during the storage period [54]. GPX activity, meanwhile, is low during the testicular phase but high between the different segments of the epididymis (i.e., caput, corpus and cauda) during maturation [54]. This 
activity pattern seems to be specifically controlled and differentiated in relation to the compartmentalization of the epididymal functions [44].

\section{Prolonged Sperm Storage in the Epididymis}

An unusual reproductive particularity in mammals, which has been reported for some bat species, is prolonged gamete storage. Though this feature occurs primarily in females in the form of delayed ovulation in relation to coupling time, cases of prolonged sperm storage have also been identified in the males of some species. In these cases, the epididymis (especially the caudal region) is the organ responsible for this function $[55,56]$.

The question of prolonged sperm storage in bats has been addressed since 1860, and this phenomenon has been identified in at least 43 species [55-59]. One of the first studies to show that the sperm of bats is capable of fertilization even after a prolonged storage period was conducted by Wimsatt and Folk in the 1940s (cited by Crichton [55]). Today we know that some bats of the Vespertilionidae and Rhinolophidae families show a temporal asynchrony in the development and functioning of the male reproductive organs [60]. Specifically, the development of the testes and the process of spermatogenesis take place mainly in the summer months, while the maximum development of the epididymis and accessory sex glands, the expression of libido, and mating, do not occur until the autumn [56, 61-64]. This asynchrony results in an unusually long period of sperm storage in the epididymis, which may extend for several months after the testes have completely regressed [55]. Indeed, the sperm in the epididymis of some bat species are stored for months, but remain viable for 4-to10 months, depending on the species and environmental conditions [65-67].

It was long considered that the phenomenon of prolonged sperm storage in bats was limited to species living in temperate and cold zones, and was attributable to the low ambient temperatures that, in turn, caused a decrease in the availability of the insects that constitute the principal source of food for those animals. As a result, those bats experienced prolonged periods of adaptive hypothermia that extended throughout the winter season [61, 68, 69]. However, later studies of bats from warmer climes where this phenomenon is also present indicated that prolonged storage is not related to low ambient temperatures $[56,60]$, though it is important to clarify that the species reported actually inhabit temperate environments because they live at high altitudes. Currently, there are reports that provide additional support for this view, since they have found regulating mechanisms that maintain sperm structurally and functionally viable during prolonged storage periods due to certain morphophysiological aspects that depend on the epididymal environment $[66,67]$.

Bats that have prolonged sperm storage typically enter into a state of lethargy early in the winter season. In this condition, individuals drastically reduce their metabolic functions and body temperature, which leads to a decrease in cellular activity and in several central functions related to reproductive processes, such as hormone production and the ability of target organs to respond to hormonal stimulation [70]. With regards to this interesting phenomenon, there are two important parameters that must be taken into account; the first is the time that the sperm remain in storage; the second is the conservation of such characteristics as viability, integrity, and the ability to perform forward movement and achieve effective fertilization. One proposal to explain how the sperm of hibernating bat species remain structurally and functionally viable for long periods in the caudal region of the epididymis was advanced by Crichton et al. [66], who determined that the epididymal fluid obtained from micropunctures of the caudal region maintain high levels of osmolarity as the storage season progresses, a condition that may favor long-term storage. Those authors [66, 67] further reported a close relation among the epididymal epithelial cells of the pallid bat (Antrozous pallidus), the northern longeared bat (Myotis septentrionalis), and the little brown bat (Myotis lucifugus), all of which form what may be called a blood-epididymal barrier, particularly during the period of sperm storage.

This phenomenon, together with the generation of a hyperosmolar environment in the lumen of the epididymal tubule, was suggested as the conditions that could cause a certain degree of dehydration of some spermatozoa and, therefore, their immobilization. Here, the cell quiescence due to reduced respiration would conserve energy and preserve viability by preventing the onset of progressive movement by the spermatozoids. Hence, lowering the osmolarity of the epididymal lumen allows the sperm to completely recover their motility and, as a result, their fertilization capacity. However, the effect of the hyperosmolar environment on sperm physiology remains to be tested with further studies.

A subsequent study by the same research group hypothesized that the plasma membrane of the sperm of the vespertilionid bat Myotis velifer apparently has greater resistance to factors such as detergents for example that are known to destabilize the sperm membrane of other mammals. At the conclusion of their experiments, however, they determined that there was no difference in terms of membrane resistance to the agents they tested. Therefore, long-term sperm survival could not be attributed to the high resistance of the plasma membrane [71].

\section{Maturation and Prolonged Storage in Mexican Big-Eared Bats (Corynorhinus mexicanus)}

Another proposal to consider relates long-term sperm storage to the epididymal maturation process. In the case of the vespertilionid Mexican big-eared bat, in addition to being a species that manifests asynchrony in the development of the male's sexual functions [56, 61-64], it also maintains the 
sperm in the epididymis for up to 5 months after the testes have fully regressed [60].

Studies of the weight, histology and morphometric variation of the epididymal tubule of $C$. mexicanus revealed that in addition to the asynchrony of the male's sexual functions, an apparent asynchrony among epididymal regions also occurs (caput-cauda), as the caput presents growth peaks in September (due to the presence of sperm), while the cauda peaks in October $\left(90.3 \times 10^{6}\right)$. Observations revealed that, anatomically-speaking, the caput of the epididymis is smaller in size than the cauda, a situation that indicates a clear asynchrony of one month between the development of these two regions $[60,72,73]$.

Sometime later, Cervantes et al. [23] conducted a study in which they analyzed separately the three regions of the epididymis (caput, corpus and cauda) of C. mexicanus. They determined that spermatozoa levels in the corpus and caput never exceeded $30 \times 106$, while data for the cauda showed a level of $77.2 \times 106$. Sperm were no longer observed in the cephalic region in early October, nor in the body at the end of that month, when sperm concentrations in the cauda were high. In addition, the presence of the cytoplasmic droplet was high in the sperm obtained from the caudal region in September (19.7\%), but showed a steady decrease until yielding zero values in late October (1.7).

Upon testing the maturational status of the sperm cells of C. mexicanus obtained from the three different regions of the epididymis by analyzing sperm capacitation and the in vitro acrosome reaction, those researchers found that the capacitation values from early September were $6 \%$ for the corpus and $16 \%$ for the cauda, but that they increased in October to $19.4 \%$ and $33.2 \%$, respectively. In the case of the acrosome reaction for the same time period, the initial values found were $7.6 \%$ and $12.0 \%$ for the body and tail, respectively, with a subsequent increase to $22.2 \%$ and $32.3 \%$, respectively. These results led them to conclude that the cauda region was not simply a sperm reservoir [74], but that in this species it is the region where sperm maturation may be completed, quite independent of the function of the testes. These findings are most interesting when we recall that the epididymis is androgen-dependent, and that the testicles of these bats have undergone complete involution, so it would seem that they have no additional effect on the epididymis [60] and that the complete differentiation of the spermatozoids could not take place there [1].

In order to strengthen support for the proposal that in $C$. mexicanus sperm maturation ends in the caudal region, Rodríguez-Tobon et al. [73] conducted studies of the morphology and ultrastructure of the spermatozoa of this species. They found a high frequency of cytoplasmic droplet in the middle section of the spermatozoa. In addition to identifying morphological changes in the different cell types of the epididymis of $C$. mexicanus, they also observed that both principal and clear cells are present in all three epididymal regions [73], and are related to the process of sperm maturation, since those cells are characterized by their highly-developed endocytic and secretory machinery and, moreover, show structural and functional differences in each region of the epididymis $[1,75]$.

Therefore, the presence of principal and clear cells throughout the epididymal tubule is evidence that the maturation process continues from the moment the sperm enter the head region of the epididymal tubule in late August, until such time as the storage period in the caudal region ends; a period that is necessary to complete the process of sperm maturation [73].

\section{Conclusions and Prospects for Epididymal Sperm Maturation in $C$. mexicanus}

Several authors have explored the mechanisms by which sperm reach maturity in the epididymis, however recent studies of the $C$. mexicanus bat have opened a new perspective to consider in relation to epididymal maturation. The fact that in this species sperm maturation is completed in the caudal epididymis region and is related to prolonged storage times leads to new considerations, given that this species is also characterized by temporal asynchrony in the development and functioning of the male's reproductive organs.

Studying the wide variety of proteins that may be secreted by the epithelial tissue of the epididymal tubule is essential to achieving a better understanding of the maturation process, since many of these proteins propitiate changes in the movement of the flagella and the subsequent recognition of the oocyte. Research into how proteins are incorporated into the spermatozoids is also essential, especially the possible role of the epididimosomes as elements in the pathway that transports them from the epididymal tissue.

Analyzing the parameters of motility using a computerized system (Computer-Assisted Sperm Analysis, or CASA) and gaining a better understanding of the various components and regions that integrate the sperm plasma membrane along the epididymal duct as the spermatozoids pass through the various organs of the male genital tract, will allow us to determine the functional status of the cells at each stage. Finally, reports in the literature affirm that the ROS in sperm allow the activation of proteins involved in flagellar movement, but additional studies are required in order to ascertain exactly what occurs in bat species characterized by long storage periods of the spermatozoids in the caudal region of the epididymis.

\section{References}

[1] Bernard Robaire, B.T.H., and Marie-Claire Orgebin-Crist, The Epididymis, in Knobil and Neill's Physiology of Reproduction, J.D. Neill, Editor. 2006.

[2] Fournier-Delpech, S., et al., Epididymal sperm maturation in the ram: motility, fertilizing ability and embryonic survival after uterine artificial insemination in the ewe. Ann. Biol. anim. Bioch Biophys, 1979. 19(3A): p. 597-605. 
[3] Brown, D. and R. Montesano, Membrane specialization in the rat epididymis. I. Rod-shaped intramembrane particles in the apical (mitochondria-rich) cell. J Cell Sci, 1980. 45: p. 187-98.

[4] Hinrichsen, M.J. and J.A. Blaquier, Evidence supporting the existence of sperm maturation in the human epididymis. $\mathrm{J}$ Reprod Fertil, 1980. 60(2): p. 291-4.

[5] Awano, M., A. Kawaguchi, and H. Mohri, Lipid composition of hamster epididymal spermatozoa. J Reprod Fertil, 1993. 99(2): p. 375-83.

[6] Cooper, T., Epididymis, in Encyclopedia of reproduction, J.D.N. E. Knovil, Editor. 1999. p. 1-17.

[7] Huang, Y., Y.W. Chung, and P.Y. Wong, Potassium channel activity recorded from the apical membrane of freshly isolated epithelial cells in rat caudal epididymis. Biol Reprod, 1999. 60(6): p. 1509-14.

[8] Legare, C., et al., Effect of vasectomy on P34H messenger ribonucleic acid expression along the human excurrent duct: a reflection on the function of the human epididymis. Biol Reprod, 2001. 64(2): p. 720-7.

[9] Vernet, P., et al., Analysis of reactive oxygen species generating systems in rat epididymal spermatozoa. Biol Reprod, 2001. 65(4): p. 1102-13.

[10] Sullivan, R., G. Frenette, and J. Girouard, Epididymosomes are involved in the acquisition of new sperm proteins during epididymal transit. Asian J Androl, 2007. 9(4): p. 483-91.

[11] Oko, R., et al., The cytoplasmic droplet of rat epididymal spermatozoa contains saccular elements with Golgi characteristics. J Cell Biol, 1993. 123(4): p. 809-21.

[12] Aitken, R.J., et al., Relative impact of oxidative stress on the functional competence and genomic integrity of human spermatozoa. Biol Reprod, 1998. 59(5): p. 1037-46.

[13] Setchell, B. and W. Breed, Anatomy, Vasculature, and Innervation of the Male Reproductive Tract, in Physiology of reproduction, E. Knobil and D. Neill, Editors. 2006, Academic Press: USA. p. 587-596.

[14] Robaire, B. and R.S. Viger, Regulation of epididymal epithelial cell functions. Biology of Reproduction, 1995. 52(2) p. 226-236.

[15] Turner, T.T., et al., Association of segmentation of the epididymal interstitium with segmented tubule function in rats and mice. Reproduction, 2003. 125(6): p. 871-8.

[16] Aitken, R.J., et al., Proteomic changes in mammalian spermatozoa during epididymal maturation. Asian J Androl, 2007. 9(4): p. 554-64.

[17] Belleannee, C., et al., Purification and identification of sperm surface proteins and changes during epididymal maturation. Proteomics, 2011. 11(10): p. 1952-64.

[18] Belleannee, C., et al., Identification of luminal and secreted proteins in bull epididymis. J Proteomics, 2011. 74(1): p. 59-78.

[19] Baker, M.A., et al., Proteomic insights into the maturation and capacitation of mammalian spermatozoa. Syst Biol Reprod Med, 2012. 58(4): p. 211-7.

[20] Contri, A., et al., Characteristics of donkey spermatozoa along the length of the epididymis. Theriogenology, 2012. 77(1): p. 166-73.
[21] Dacheux, J.L., et al., The contribution of proteomics to understanding epididymal maturation of mammalian spermatozoa. Syst Biol Reprod Med, 2012. 58(4): p. 197-210.

[22] Amann, R.P. and B.D. Schanbacher, Physiology of male reproduction. Journal of animal science, 1983. 57 Suppl 2: p. $380-403$.

[23] Cervantes, M.I., et al., Spermatozoa epididymal maturation in the Mexican big-eared bat (Corynorhinus mexicanus). Syst Biol Reprod Med, 2008. 54(4-5): p. 196-204.

[24] White, D.R. and R.J. Aitken, Influence of epididymal maturation on cyclic AMP levels in hamster spermatozoa. Int J Androl, 1989. 12(1): p. 29-43.

[25] Yeung, C.H., G.F. Weinbauer, and T.G. Cooper, Responses of monkey epididymal sperm of different maturational status to second messengers mediating protein tyrosine phosphorylation, acrosome reaction, and motility. Mol Reprod Dev, 1999. 54(2): p. 194-202.

[26] Vijayaraghavan, S., et al., A Role for Phosphorylation of Glycogen Synthase Kinase-3 $\alpha$ in Bovine Sperm Motility Regulation. Biology of Reproduction, 2000. 62(6): p. 16471654.

[27] Tardif, S., et al., Capacitation is associated with tyrosine phosphorylation and tyrosine kinase-like activity of pig sperm proteins. Biol Reprod, 2001. 65(3): p. 784-92.

[28] Urner, F. and D. Sakkas, Protein phosphorylation in mammalian spermatozoa. Reproduction, 2003. 125(1): p. 1726.

[29] Naz, R.K. and P.B. Rajesh, Role of tyrosine phosphorylation in sperm capacitation/acrosome reaction. Reprod Biol Endocrinol, 2004. 2: p. 75.

[30] Lewis, B. and R.J. Aitken, Impact of epididymal maturation on the tyrosine phosphorylation patterns exhibited by rat spermatozoa. Biol Reprod, 2001. 64(5): p. 1545-56.

[31] Rodríguez-Tobón, A., et al., Tyrosine phosphorylation as evidence of epididymal cauda participation in the sperm maturation process of the Corynorhinus mexicanus bat., in Acta Zoologica-stockholm, In press. 2015.

[32] Baldi, E., et al., Intracellular calcium accumulation and responsiveness to progesterone in capacitating human spermatozoa. J Androl, 1991. 12(5): p. 323-30.

[33] Baker, M.A., et al., Analysis of the mechanism by which calcium negatively regulates the tyrosine phosphorylation cascade associated with sperm capacitation. J Cell Sci, 2004. 117(2): p. 211-22.

[34] Chabory, E., et al., Mammalian glutathione peroxidases control acquisition and maintenance of spermatozoa integrity. J Anim Sci, 2010. 88(4): p. 1321-31.

[35] Turrens, J.F., Mitochondrial formation of reactive oxygen species. The Journal of Physiology, 2003. 552(2): p. 335-344.

[36] de Lamirande, E., et al., Reactive oxygen species and sperm physiology. Rev Reprod, 1997. 2(1): p. 48-54.

[37] Bauskin, A.R., I. Alkalay, and Y. Ben-Neriah, Redox regulation of a protein tyrosine kinase in the endoplasmic reticulum. Cell, 1991. 66(4): p. 685-96. 
[38] Aitken, R.J., et al., Redox regulation of tyrosine phosphorylation in human spermatozoa and its role in the control of human sperm function. J Cell Sci, 1995. 108 (5): p. 2017-25.

[39] Leclerc, P., E. de Lamirande, and C. Gagnon, Regulation of protein-tyrosine phosphorylation and human sperm capacitation by reactive oxygen derivatives. Free Radic Biol Med, 1997. 22(4): p. 643-56.

[40] Caselli, A., et al., The inactivation mechanism of low molecular weight phosphotyrosine-protein phosphatase by H2O2. J Biol Chem, 1998. 273(49): p. 32554-60.

[41] Aitken, R.J., Possible redox regulation of sperm motility activation. J Androl, 2000. 21(4): p. 491-6.

[42] Baker, M.A. and R.J. Aitken, The importance of redox regulated pathways in sperm cell biology. Mol Cell Endocrinol, 2004. 216(1-2): p. 47-54.

[43] Ford, W.C., Regulation of sperm function by reactive oxygen species. Hum Reprod Update, 2004. 10(5): p. 387-99.

[44] Arenas-Ríos, E., Enzimas anti-especies reactivas de oxígeno, como reguladores en los procesos de espermatogénesis maduración y almacenamiento prolongado de espermatozoides en el murciélago Corynorhinus mexicanus. . 2009, Universidad Autónoma Metropolitana México.

[45] Baker, M.A., et al., Identification of cytochrome-b5 reductase as the enzyme responsible for NADH-dependent lucigenin chemiluminescence in human spermatozoa. Biol Reprod, 2005. 73(2): p. 334-42.

[46] Baker, M.A., et al., Identification of gene products present in Triton X-100 soluble and insoluble fractions of human spermatozoa lysates using LC-MS/MS analysis. Proteomics Clin Appl, 2007. 1(5): p. 524-32.

[47] Alvarez, J.G. and B.T. Storey, Role of superoxide dismutase in protecting rabbit spermatozoa from $\mathrm{O} 2$ toxicity due to lipid peroxidation. Biol Reprod, 1983. 28(5): p. 1129-36.

[48] Nissen, H.P. and H.W. Kreysel, Superoxide dismutase in human semen. Klinische Wochenschrift, 1983. 61(1): p. 63-65.

[49] Alvarez, J.G., et al., Spontaneous lipid peroxidation and production of hydrogen peroxide and superoxide in human spermatozoa. Superoxide dismutase as major enzyme protectant against oxygen toxicity. J Androl, 1987. 8(5): p. 338-48.

[50] Alvarez, J.G. and B.T. Storey, Role of glutathione peroxidase in protecting mammalian spermatozoa from loss of motility caused by spontaneous lipid peroxidation. Gamete Res, 1989. 23(1): p. $77-90$

[51] Jeulin, C., et al., Catalase activity in human spermatozoa and seminal plasma. Gamete Res, 1989. 24(2): p. 185-96.

[52] Halliwell, B. and J.M.C. Gutteridge, Free Radicals in Biology and Medicine. 2007: Oxford University Press.

[53] Zini, A., E. de Lamirande, and C. Gagnon, Reactive oxygen species in semen of infertile patients: levels of superoxide dismutase- and catalase-like activities in seminal plasma and spermatozoa. Int J Androl, 1993. 16(3): p. 183-8.

[54] Arenas-Ríos, E., et al., Superoxide dismutase, catalase, and glutathione peroxidase during epididymal maturation and prolonged storage of spermatozoa in the Mexican big-eared bat (Corynorhinus mexicanus). Canadian Journal of Zoology, 2005. 83(12): p. 1556-1565.
[55] Crichton, E.G. and P.H. Krutzsch, Reproductive Biology of Bats. 2000: Elsevier Science.

[56] Krutzsch, P.H., The Reproductive Biology of the Cave Myotis (Myotis velifer). Acta Chiropterologica, 2009. 11(1): p. 89-104.

[57] Sharifi, M., et al., Evidence of sperm storage in Pipistrellus kuhlii (Chiroptera: Vespertilionidae) in western Iran. Folia Zoologica, 2004. 53: p. 1-6.

[58] Sharifi, M., V. Akmali, and G. Rostam, Evidence of sperm storage in Myotis capaccinii (Chiroptera: Vespertilionidae) in western Iran. . Journal of Veterinary Research, 2008. 63(2): p. 63-67.

[59] Wang, Z., et al., Epididymal sperm storage in Rickett's bigfooted bat (Myotis ricketti). Acta Chiropterologica, 2008. 10(1): p. 161-167.

[60] León-Galván, M.A., et al., Male reproductive cycle of mexican big-eared bats, corynorhinus mexicanus (chiroptera: vespertilionidae). The Southwestern Naturalist, 2005. 50(4): p. 453-460.

[61] Gustafson, A.W., Male reproductive patterns in hibernating bats. J Reprod Fertil, 1979. 56(1): p. 317-31.

[62] Krishna, A. and K. Singh, The relationship between testicular activity, accessory sex glands, and circulating steroid concentration during the reproductive cycle in a male Indian vespertilionid bat, Scotophilus heathi. Canadian Journal of Zoology, 1997. 75(7): p. 1042-1050.

[63] Krishna, A. and K. Singh, Changes in the thyroid gland during the reproductive cycle of the male vespertilionid bat, Scotophilus heathi. Revista Brasileira de Biologia, 1998. 58: $\mathrm{p}$ 707-716.

[64] Krishna, A. and K. Singh, Asynchrony of the reproductive organs of the male vespertilionid bat, Scotophilus heathi: role of gonadotrophins. Acta Theriologica 1999. 44(2): p. 123-131.

[65] Racey, P.A., The prolonged storage and survival of spermatozoa in Chiroptera. J Reprod Fertil, 1979. 56(1): p. 391-402.

[66] Crichton, E.G., et al., Unique features of the cauda epididymidal epithelium of hibernating bats may promote sperm longevity. Anat Rec, 1993. 237(4): p. 475-81.

[67] Crichton, E.G., et al., Hyperosmolality and sperm storage in hibernating bats: prolongation of sperm life by dehydration. Am J Physiol, 1994. 267(5-2): p. R1363-70.

[68] Krutzsch, P.H., Male reproductive patterns in nonhibernating bats. J Reprod Fertil, 1979. 56(1): p. 333-44.

[69] Jolly, S.E. and A.W. Blackshaw, Prolonged epididymal sperm storage, and the temporal dissociation of testicular and accessory gland activity in the common sheath-tail bat, Taphozous georgianus, of tropical Australia. J Reprod Fertil, 1987. 81(1): p. 205-11.

[70] Wimsatt, W., Some problems of reproduction in relation to hibernation in bats. . Bulletin of the Museum of Comparative Zoology Harvard 1960. 124: p. 249-267.

[71] Crichton, E.G., P.H. Krutzsch, and R. Yanagimachi, Stability of the sperm plasma membrane of hibernating bats (Myotis velifer) compared with other mammals. J Reprod Fertil, 1993. 97(1): p. 1-4. 
[72] León-Galvan, M.A., et al., Prolonged storage of spermatozoa in the genital tract of female Mexican big-eared bats (Corynorhinus mexicanus): the role of lipid peroxidation. Canadian Journal of Zoology, 1999. 77(1): p. 7-12.

[73] Rodríguez-Tobón, A., Análisis macro y micro estructural del epidídimo en relación con la maduración y almacenamiento de espermatozoides en el murciélago estacional Corynorhinus mexicanus. . 2011, Universidad Autónoma Metropolitana México.
[74] Holland, M.K., J.T. Vreeburg, and M.C. Orgebin-Crist, Testicular regulation of epididymal protein secretion. J Androl, 1992. 13(3): p. 266-73.

[75] Robaire, B., B. Hinton, and C. Orgebin-Crist, The Epididymis: From Molecules to Clinical Practice: From Molecules to Clinical Practice: a Comprehensive Survey of the Efferent Ducts, the Epididymis and the Vas Deferens. 2001: Springer US. 